\title{
Envelhecimento e trabalho na sociedade capitalista
}

\author{
Maria Augusta Tavares ${ }^{1}$ \\ https://orcid.org/0000-0002-4527-5193 \\ ${ }^{1}$ Universidade Nova de Lisboa, Instituto de História Contemporânea, Lisboa, LX, Portugal
}

\section{Envelhecimento e trabalho na sociedade capitalista}

Resumo: Pensado para subsidiar uma conferência que, por incompatibilidade entre a data do evento e a minha agenda, não foi realizada, este ensaio discute o envelhecimento do trabalhador na sociedade capitalista, sob o neoliberalismo. É um chamamento à unificação da classe trabalhadora, tendo em vista desvelar a trama capitalista, para que, juntos, trabalhadores manuais e intelectuais se reconheçam capazes de romper com os valores burgueses e de pensar criticamente numa sociedade que não subestime a nossa humanidade.

Palavras-chave: Envelhecimento. Trabalho. Capitalismo.

\section{Aging and Work in the Capitalist Society}

Abstract: This essay was first written to subsidize a conference that did not happen because of scheduling problems and discusses workers' aging in a capitalist society marked by the neoliberalism. The intention here is to raise awareness for the union of the working class to unveil the capitalist plot. Manual and intellectual workers, together, must acknowledge their ability to break with bourgeois values and critically think of a society that does not underestimate our humanity.

Keywords: Aging. Work. Capitalism.

Recebido em 28.01.2019. Aprovado em 17.09.2019. Revisado em 28.11.2020.

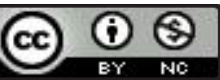

C O(s) Autor(es). 2020 Acesso Aberto Esta obra está licenciada sob os termos da Licença Creative Commons Atribuição-NãoComercial 4.0 Internacional (https://creativecommons.org/licenses/by-nc/4.0/deed.pt_BR), que permite copiar, distribuir e reproduzir em qualquer meio, bem como adaptar, transformar e criar a partir deste material, desde que para fins não comerciais e que você forneça o devido crédito aos autores e a fonte, insira um link para a Licença Creative Commons e indique se mudanças foram feitas. 


\section{Introdução}

Convidada a falar sobre envelhecimento, o meu primeiro movimento foi dizer não. Ora, para além do envelhecimento enquanto um processo no qual, por absoluta falta de opção, estou a ser mergulhada, pergunteime o que sabia acerca desse tema. Honestamente? Sei pouco. Fui convencida, no entanto, quando, depois de muita argumentação, pactuamos - eu e a minha insistente interlocutora - que eu estaria capacitada a falar sobre envelhecimento e trabalho na perspectiva da totalidade social.

O tema, como se pode inferir, dispensa maiores explicações, contudo nunca é demais esclarecer. Não terão nenhum prazer de participar desse debate os que se orientam pelo pensamento pós-moderno, esse pessoal que nega a centralidade da razão dialética e, por conseguinte, recusa a tradição marxista e as suas postulações de análise do movimento real. Aqui, a categoria trabalho será analisada como fundante do ser social. Entende-se que por mais que o trabalho seja fragmentado, por mais que os neoliberais tentem obscurecêlo e negá-lo como fonte de riqueza, a meu juízo, a centralidade do trabalho e o pensamento de Marx continuam absolutamente atuais. Atualidade que, a meu ver, a realidade atesta. E não estou sozinha nessa convicção. Entre muitos nomes reconhecidos pela comunidade acadêmica, destaco o de Pietro Basso (2018), segundo o qual o tempo de trabalho está, historicamente, no centro de todas as dinâmicas entre capital e trabalho, e um mínimo de senso histórico é suficiente "para a compreensão de que em nenhuma outra época ou forma de sociedade o trabalho e o tempo de trabalho tiveram tanta centralidade social e pessoal" (BASSO, 2018, p. 54). Em acordo com este pensamento, agora sou eu quem chama a pensar sobre o envelhecimento.

Não é preciso ser um especialista para saber que o envelhecimento diz respeito a uma fase cujas transformações consubstanciam objetos de estudo de muitas áreas do conhecimento. Essas pesquisas, no entanto, são geralmente fundadas em visões biológicas ou demográficas, as quais, por razões óbvias, não serão aqui abordadas. Com isso, não estou a negar ou a reduzir o seu grau de importância para a ciência, apenas quero deixar claro que como essas visões se apoiam em elementos generalizantes, que redundam na uniformização do fenômeno estudado, é óbvio que caminharei por outra trilha, nomeadamente a que se coaduna com a perspectiva já referenciada.

A prioridade, portanto, é tomar o envelhecimento como um fenômeno que sofre determinações históricas, políticas, econômicas, sociais e culturais. Em sendo assim, o nosso estudo está direcionado ao envelhecimento dos que vivem do trabalho. Para ser breve e sintonizada com o presente, direi que se trata de confrontar uma dupla precarização, pois o trabalhador contemporâneo é, em geral, precarizado, e o envelhecimento, por sua vez, tende ao agravamento dessa precarização, uma vez que o Estado, em lugar de premiar o trabalhador idoso, castiga-o, por tornar-se menos produtivo e pela inevitável inatividade.

Nessa trilha, a reforma da previdência, em curso no Brasil, está a indicar que o trabalhador assalariado só deve ser pago quando estiver a produzir valor. O Estado, ou o "dispositivo Estado/mercado", como bem o define Dardot e Laval (2016), só está interessado em indivíduos cujas escolhas e possibilidades redundem nos objetivos do mercado. Para ficar apenas na discussão sobre a aposentadoria, atualmente, em maior ou menor grau, sobretudo na periferia do mundo, a exemplo do Brasil, o direito coletivo está a ser individualizado e transfigurado em mercadoria. Considerando que milhões de trabalhadores mal ganham o suficiente para uma escassa sobrevivência, pode-se prever que, se aprovada a reforma, muitos brasileiros não viverão a experiência da aposentadoria, uns por serem inelegíveis e outros por morrerem antes de vir a ser. Daí por que julgamos ser necessário suscitar o debate sobre o trabalho, e não só na academia, mas principalmente entre os trabalhadores manuais, novos e velhos, pois, dadas a inexorabilidade do envelhecimento e a explícita posição do Estado a favor do capitalismo financeiro, a luta por direitos, nessa fase da vida, torna-se indissociável dos interesses de todos os que vivem do trabalho.

\section{Trabalho e relações sociais}

Orientada pela totalidade social, tenho analisado o trabalho nas formas precarizadas e informais por toda a minha vida acadêmica. A centralidade do trabalho me é tão palpável, que não ter o trabalho como fundante me parece ou uma falsidade ou uma enorme ignorância. No primeiro caso, é claro, para justificar interesses contrários à classe trabalhadora. Entretanto, o que entendo por falsidade foi e continua sendo disseminado com tanta competência, que se tornou o pensamento dominante. Estaria Freud correto ao dizer que a massa só é excitada por estímulos excessivos? "Quem quiser agitá-la não precisa de argumentar logicamente, basta utilizar imagens fortes para pintar, exagerar e repetir sem parar a mesma coisa" (MBEMBE, 2017, p. 85). Bem, apesar dos recentes resultados conseguidos pelas fake news e apesar de conhecer muitos pobres que defendem o pensamento liberal com a propriedade de um capitalista, penso que a afirmação freudiana não se aplica à elucidação da centralidade do trabalho. Não se trata aqui de excitar a 
massa, mas de estimular a consciência crítica dos trabalhadores, de suscitar perguntas cujas respostas apontem para o nosso pertencimento de classe e, portanto, indiquem o lado em que devemos estar.

Por que, para isso, recorro ao pensamento marxista?

Trabalho desde o início da adolescência. Essa precocidade foi geradora de uma revolta muda e de perguntas recorrentes, geralmente dirigidas aos dois sujeitos a quem eu atribuía o dever de me proteger: meu pai e meu Deus. Sim, eu já tive um Deus. Tanto as perguntas quanto a resposta foram sempre pautadas por silêncio e dor. Como me ensinaram que Deus tudo sabia e tudo podia, eu costumava lhe perguntar por que sendo tão poderoso, permitia que aos 12 anos uma menina fosse obrigada a trabalhar. Ao meu pai, apesar de me sentir injustiçada, eu nunca consegui dar voz à pergunta. A resposta, por sua vez, vinha em forma de condenação, porque o pai presente não me poupava e o Outro, hierarquicamente superior, devia estar ocupado com seguidores mais fiéis. Afinal, a Ele entregam tudo que parece não ter solução.

$\mathrm{Na}$ fase adulta, por caminhos tortuosos, muitas vezes ouvindo o galo cantar sem saber onde, cheguei ao pensamento marxista. Percebi, então, que andara a fazer a pergunta errada aos sujeitos errados. Percebi que culpava o meu pai por uma exigência socialmente determinada, pois, acima de nós não estava Deus, mas uma velha senhora a que chamamos de sociedade capitalista, que lhe fazia exigências bem mais extremas do que aquelas que eram feitas por ele a mim. Ela o obrigava, inclusive, a ser mau comigo. E, por mais que, nas suas curtas noites, envergonhada e silenciosamente ele se culpasse por não ser o pai protetor, sua vontade era suplantada pela condição de classe a que nós pertencíamos.

A proximidade com o pensamento marxista me fez concluir que a velha senhora não agia sozinha, era sustentada por Deus e pelo Estado. Entendi que, para que a desigualdade social não fosse questionada, era importante fazer as pessoas acreditarem - principalmente os trabalhadores - que todos são iguais diante de Deus e do Estado. Com esse artifício, os ricos têm uma imensa margem para manobrar a exploração do trabalho. Riqueza e pobreza - fenômenos sociais - passam a ser vistas como naturais. Afinal, Deus "quis", por razões que não cabe explicar, aqui e agora, que uns nascessem pobres e outros ricos, e sob essa premissa é suposto que o trabalhador não ousa fazer perguntas que possam desmascarar a farsa capitalista.

Mary Gabriel, historiadora que escreveu Amor e Capital (2013), diz que Marx observou a religião e viu o reflexo do sofrimento do homem. Concluiu que a religião havia sido criada pelo homem, que a utilizava como uma droga para aliviar sua dor, num mundo em que ele se sentia impotente para mudar. A religião, comumente tratada como tema teológico, é analisada por Marx como tema social e político. É conhecida a afirmação feita por ele em Crítica da Filosofia do Direito de Hegel: "A religião é o suspiro da criatura oprimida, o sentimento de um mundo cruel e a alma de circunstâncias desalmadas. A religião é o ópio do povo.” (MARX, 2010, p. 140).

Ao viés religioso convém que se acrescente o estatuto de pertencimento social a uma sociedade que, formalmente, atribui igualdade a todos, mediante o conceito jurídico-político de cidadania. Essa combinação repetida e disseminada pelos meios de comunicação que, hoje, têm alcance mundial, mantém a grande maioria dos trabalhadores sob a alienação desejável, para que o padrão de sociedade que os hostiliza, contraditoriamente, seja por eles legitimado.

A esse respeito, Dardot e Laval (2016) afirmam que

[...] o efeito procurado pelas novas práticas de fabricação e gestão do novo sujeito é fazer com que o individuo trabalhe para a empresa como se trabalhasse para si mesmo e, assim, elimine qualquer sentimento de alienação e até mesmo qualquer distância entre o individuo e a empresa que o emprega. Ele deve trabalhar para sua própria eficácia, para a intensificação de seu esforço, como se essa conduta viesse dele próprio, como se esta lhe fosse comandada de dentro por uma ordem imperiosa de seu próprio desejo, à qual ele não pode resistir. (DARDOT; LAVAL, 2016, p. 327).

Pois bem, se os trabalhadores, majoritariamente, foram tornados incapazes de pensar criticamente, ainda há intelectuais de quem se espera essa capacidade. Contudo, há mais intelectuais a defender o capital que o trabalho. O pensamento carrega sempre uma ideologia, o que, aliás, revela a classe social com a qual se alinha o pensador.

Segundo Kumar (1997, p. 47), as ideologias

não são simplesmente ideias na cabeça de alguém, mas práticas concretas, tão reais como quaisquer outras práticas sociais. São realidades vívidas. Limitam-nos o pensamento sobre nós mesmos e o mundo em que vivemos e, dessa maneira, revestem-se de consequências práticas.

As nossas ideias jamais são neutras. Seguramente, no capitalismo, elas são reveladoras da contradição entre capital e trabalho. Isso, no entanto, não significa que as ideias são sempre expostas como se 
representassem fielmente os interesses de uma classe. Sobretudo quem advoga os interesses do capital, tenta mascarar o seu objetivo: em lugar da oposição entre as classes, as ideias jogam com o bem e o mal, nos quais cabe uma infinidade de contradições.

Nesse contexto, há intelectuais que ensaiam uma neutralidade, apontando problemas e soluções, como se a contradição capital/trabalho fosse semelhante aos cordões azul e encarnado do pastoril1 ${ }^{1}$. Há outros que assumem declaradamente a perspectiva do capital, pautados pela noção liberal de que o desenvolvimento econômico beneficia tanto os pobres como os ricos. Grande treta! Em nenhuma circunstância, no capitalismo, ricos e pobres são iguais. A farsa da igualdade remete a uma passagem do livro Amor e Capital: "Os pobres roubavam o que podiam dos ricos e os ricos roubavam o que podiam do trabalhador pobre - a uma coisa se chamava crime, a outra de indústria" (GABRIEL, 2013, p. 127). Dois pesos e duas medidas, regra com a qual nos defrontamos cotidianamente. Contudo, os pensadores, sustentados pela concepção liberal (agora neoliberal), colocam-se no mundo como se fossem a representação do Bem a lutar contra os representantes do Mal - os defensores de direitos dos trabalhadores -, tomando como justificativa o desenvolvimento. A velha ideia que separa a economia da questão social é advogada, apelando-se sempre para a paciência dos trabalhadores, ou para a resiliência, uma palavra muito em moda, porque é indicativa de uma conformação, de fazer com que o sujeito se amolde à sua suposta má sorte.

Por sua vez, a suposta representação do Mal, também conhecida como esquerda, se distingue por não abrir mão da centralidade do trabalho. Para esses, o capitalismo não é uma entidade suprema à qual os trabalhadores devem se curvar. Malgrado reconhecerem o seu fim, esses intelectuais não negam o caráter civilizatório do capitalismo, na sua fase inicial de desenvolvimento, contudo percebem que esse modo de produção tornou-se destrutivo e que, portanto, qualquer tentativa de expansão do mercado, contemporaneamente, esbarra em determinações que podem inviabilizar a vida no planeta. Para esses, os chamados problemas sociais não existem isoladamente, mas interconectados, sendo, portanto, expressões que consubstanciam a questão social, única e ineliminável, se a saída oferecida forem as medidas paliativas que, vez por outra, para parecer estar acima das classes, o Estado oferece. Os intelectuais a quem me refiro entendem que extinguir a questão social implica a extinção da sua causa, o modo de produção capitalista. Coloco-me entre eles e orgulho-me de, cotidianamente, confrontar a sociedade capitalista para analisar, criticar e fazer as perguntas que gostaria fossem feitas por todos os trabalhadores. Entre muitas outras, pergunto agora: o trabalho precisa do capital ou o capital precisa do trabalho?

A resposta a essa pergunta, por certo, é geradora de outras perguntas, as quais, se conduzidas com base no movimento do real, podem levar ao desvelamento da trama capitalista.

Em sã consciência, alguém diria que incentivar os tra-

\section{[...] o tempo de trabalho está,}

historicamente, no centro de

todas as dinâmicas entre capital e trabalho $[\ldots]$ balhadores a pensar sobre a sua realidade faz dos intelectuais marxistas indivíduos de mentes perigosas? Procede inferir que fazer perguntas ao real tem o propósito de destruir a paz social? De fato, são perguntas que questionam a sociedade capitalista. Mas se a velha senhora quer o bem de todos, como em geral suas personificações propagam, por que não podemos the fazer perguntas que elucidem a desigualdade social? Pois bem, são perguntas com esse teor que têm levado o governo brasileiro a demonizar pesquisadores e professores. São perguntas com esse teor que justificam o discurso condenatório contra "perigosíssimos" comunistas, acusados de um crime denominado marxismo cultural. São perguntas com esse teor que explicam a "Escola sem Partido", a extinção de cursos na área das Ciências Humanas, os cortes de recursos à universidade pública. São perguntas com esse teor que explicam o fato de o governo esconder os números que, supostamente, servem de base para a reforma da Previdência.

Correndo o risco de ser vista como uma perigosa comunista, eu os convido a pensar. Como já vimos, só podemos pensar a partir do crivo de classe: ou se é capitalista ou trabalhador. Ou você se coloca do lado do trabalho ou do lado do mercado. Não há um meio-termo. Não há dúvida que a manutenção da sociedade depende do trabalho e, se este não for realizado, a existência da humanidade torna-se completamente inviabilizada. $\mathrm{O}$ fato de chegarem a nós como mercadoria quase todas as coisas de que precisamos pode levar a que se pense no trabalho como uma abstração, mas isso é falso. Por mais barreiras sociais que, atualmente, existam entre o trabalho e o alimento que chega à nossa mesa, na forma de mercadoria, ele é resultado do trabalho. É verdade que o capitalismo do século XXI não é exatamente igual ao dos séculos anteriores, mas, malgrado as transformações, não só o trabalho continua central, como o aumento da produtividade não implica redução das jornadas de trabalho, o que fortalece as convicções aqui defendidas. 
Pietro Basso (2018) mostra que as transformações do trabalho ocorridas no século XX desmentem as convicções triunfalistas da ciência e da técnica, pelas quais seria possível combinar desenvolvimento da economia e da produtividade com aumento do tempo livre dos trabalhadores. A regra identificada por ele, a esse respeito, é exatamente o oposto: "no século XX, a redução da jornada de trabalho na indústria foi, e ainda é inversamente proporcional à elevação dos investimentos, ao progresso técnico e ao aumento da produtividade" (BASSO, 2018, p. 45). Paradoxalmente, o aumento da produtividade no capitalismo tornou mais problemática a redução da jornada do trabalho, fenômeno que, segundo o mesmo autor, pode ser chamado de paradoxo da produtividade do trabalho, tendo em vista que as economias mais ricas são exemplares na prática das jornadas longas. Nessa trilha, os Estados Unidos seguiram o Japão nos anos 1970 e 1980 e, agora, a Europa segue os dois para recuperar a sua economia.

Constata-se que a base do capitalismo foi e continuará sendo o trabalho. Os trabalhadores não sobrevivem porque generosamente são empregados por capitalistas. Não. Os trabalhadores existem porque sem eles o capitalismo não existiria, embora, equivocadamente e por má-fé, os trabalhadores sejam tratados como se estivessem em dívida com os seus empregadores. De fato, há uma dívida impagável, mas não é o trabalhador que deve ao capitalista, é exatamente o contrário.

Não tenho certeza se as minhas elucubrações estão a conduzir o leitor em direção ao objetivo que declarei inicialmente. Por isso, reafirmo: o meu propósito não é falar do envelhecimento em geral. $\mathrm{O}$ foco, aqui, são trabalhadores que envelhecem, e se a sobrevivência do trabalhador está a se tornar impraticável, procede supor que em face do envelhecimento será ainda mais difícil, dadas as transformações físicas, emocionais e sociais a que o velho é submetido. A meu juízo, em face das sucessivas crises do capital, convertidas em crise do trabalho, não basta que uma minoria de sujeitos pense sobre o trabalho. Afinal, "cada crise acelera a centralização dos capitais e faz crescer o proletariado" (MARX, 2009, p. 127). Convém que as perguntas que movem os pesquisadores marxistas sejam feitas conjuntamente com aqueles que estão a sofrer mais intensamente a precarização do trabalho. São os elementos da realidade que elucidam as teses defendidas pelos pesquisadores, donde decorre a imensa importância de ter um olho na teoria e outro na realidade (MARX, 2009).

Enquanto escrevo este artigo, por um lado, ministros do governo, senadores, deputados, juristas etc. estão mobilizados no sentido de obter aprovação à reforma da Previdência brasileira, que penaliza principalmente os trabalhadores mais pobres, os velhos em particular. E, por outro, o envelhecimento de que tratamos se faz representar nas famílias, nas ruas, nos hospitais, nos lares de idosos a maioria são velhos pobres, em muitos casos, sozinhos, tristes, abandonados, sem condição de atendimento às necessidades básicas. No Japão, uma das sociedades mais ricas do mundo, há registros de muitos idosos que se esforçam para serem presos. Perguntado a um deles se gostava de ficar na prisão, respondeu: "Não é que eu goste, mas posso ficar lá de graça" (BBC NEWS, 2019). Convém ressaltar que estamos a falar de idosos aposentados, numa sociedade rica. Realidade bem diferente da dos países onde a velhice, muitas vezes, não atende aos critérios de elegibilidade para garantir o direito à aposentadoria, sendo, portanto, submetida a condições de extrema pobreza. No caso brasileiro, será que os velhos sabem que a maioria dos senhores e senhoras que estão a decidir sobre o seu destino são absolutamente contrários aos seus interesses?

Pois bem, imaginemos trabalhadores aposentados ou prestes a se aposentar que fossem capazes de fazer perguntas elucidativas das mentiras que lhes foram imputadas pelo capital, pelo Estado e por intelectuais de direita, ao longo de toda a vida. Certamente, a velha senhora teria dificuldade em explicar por que quer pagar as dívidas do capital com o sacrifício do trabalho. Em sendo assim, mesmo correndo o risco de ser cansativa, insisto na pergunta sobre a qual eu gostaria que os trabalhadores discutissem entre si: o trabalho precisa do capital ou o capital precisa do trabalho?

O modo como, historicamente, se organiza a produção traduz uma longa experiência de exploração do homem pelo homem. A humanidade já conviveu com o escravismo, o feudalismo e, agora, com o capitalismo. Todas essas formações sociais são compostas por classes antagônicas, isto é, por dominantes e dominados. Significa dizer que em todos esses momentos históricos houve ricos e pobres. No entanto, isso não é argumento suficiente para afirmar que a divisão da sociedade em classes seja algo natural. "A Natureza não produz de um lado possuidores de dinheiro e de mercadorias e, de outro, meros possuidores das próprias forças de trabalho" (MARX, 1983, p. 140). O salto que foi dado entre o escravismo e o capitalismo é inegável, mas insatisfatório. "Engels concluiu que a única diferença entre escravos e operários era que os escravos eram vendidos para o resto da vida, enquanto os operários se vendiam a si mesmos dia após dia" (GABRIEL, 2013, p. 106). Considerando as estratégias usadas pelo neoliberalismo para usar a força de trabalho sem que os capitalistas precisem comprá-la, o ato de vender-se ou de não ter quem o compre rompe o pacto que está na origem do capitalismo. Ainda assim, não falta quem defenda esse modo de produção, como se fora o ápice do desenvolvimento social.

Se a desigualdade social é questionada, logo alguém argumenta que as diferenças sociais se explicam numa característica natural: o homem é egoísta, portanto, sendo essa a essência humana, torna-se impossível 
eliminar a desigualdade. Trata-se, ao mesmo tempo, de negar a centralidade do trabalho como criador de riqueza e de tentar convencer a classe trabalhadora de que o capitalismo, por ser a forma mais desenvolvida das revoluções econômicas, constitui o fim da História. Assim, só resta assumir uma atitude conformista de se adequar a essa condição irreversível, contra a qual é estúpido lutar.

Este argumento deve ser aceito como verdade ou deve ser questionado? Não é o caso de se procurar saber quem são os advogados dessa ideia? Que interesses moveriam os defensores da sociedade a convencer os pobres à aceitação de sacrifícios, para que os ricos continuem acumulando, enquanto o Estado está a lhes retirar os direitos fundamentais à vida?

Evidente que as respostas a tais questões só podem ser encontradas no interior do desenvolvimento das relações de produção. Entretanto, penso - sem querer parecer arrogante - que a maioria dos trabalhadores não está capacitada a perceber a teia de relações de que o capitalismo se vale para justificar a sua desmedida gana por acumulação. Isso, no entanto, não serve como justificativa para que a desigualdade seja ignorada. Se, de fato, importa questioná-la, deve-se começar a pensar, tendo como ponto de partida elementos que são fundantes dessa sociedade e que permeiam o cotidiano da relação capital-trabalho, o que os trabalhadores, mesmo não sendo capazes de elaborar teoricamente, experienciam ao longo da vida profissional.

Falar do capitalismo implica falar de mercadoria e dinheiro, embora mercadoria e dinheiro já existissem muito antes de a sociedade ser capitalista. Na verdade, o diferencial reside no fato de que apenas nesta sociedade esses dois elementos podem se tornar capital. A mercadoria, na sociedade capitalista, satisfaz a quase todas as necessidades, não importa "se elas se originam do estômago ou da fantasia" (MARX, 1983, p. 45). Alimento, educação, saúde, segurança, lazer, para ficar apenas nas necessidades mais gerais, tudo está no mercado para ser vendido. E, desde que o trabalhador foi separado dos meios de produção e transformado em assalariado, a sua sobrevivência está submetida à venda da única mercadoria da qual ele dispõe: a força de trabalho.

O capitalista, dono dos meios de produção, não por acaso, é também dono de todas as outras mercadorias. Assim, para que o trabalhador possa, no mercado, adquirir alimentação, roupas, moradia e outras mercadorias necessárias a si e à sua família, ele precisa trocar a sua força de trabalho por dinheiro. Com esse dinheiro, o trabalhador vai ao mercado e compra as mercadorias que o capitalista julga necessárias à sua manutenção, de modo que o seu dinheiro é imediatamente consumido. O dinheiro do capitalista, ao contrário, cada vez mais se multiplica. Como se explica que ambos trabalhador e capitalista sejam vendedores de mercadoria e somente um enriquece, enquanto o outro empobrece?

Segundo Marx, para transformar dinheiro em capital, o possuidor de dinheiro precisa encontrar, no mercado de mercadorias, trabalhadores que disponham livremente de sua força de trabalho e que não tenham nenhuma outra mercadoria para vender, além dessa. Como qualquer outra mercadoria, o valor da força de trabalho está determinado antes de entrar em circulação. Mas, enquanto as outras mercadorias propriedades do capitalista são vendidas/consumidas pelo seu valor real, a força de trabalho, pela peculiaridade de ser fonte de valor, é uma mercadoria, aliás a única, que ao ser consumida, valoriza e preserva o capital.

\section{Ora, por que isso ocorre?}

Diferentemente das outras mercadorias, o trabalhador deixa que a sua força de trabalho seja consumida pelo comprador antes de receber o pagamento do seu preço. Preço este que, ao invés de ser pago por quem vai usar a mercadoria, é o próprio vendedor (o trabalhador) que adianta ao comprador (o capitalista), através do que está produzindo. E, como se não bastasse o trabalhador adiantar ao capitalista o seu salário, o preço da força de trabalho, fixado contratualmente, não corresponde ao valor de uso que dela faz o seu comprador. Apenas parte do que o trabalhador produz é paga. Graças a essa armadilha, há em todas as mercadorias vendidas pelo capital um elemento pelo qual ele não pagou, o que lhe permite transformar o seu dinheiro em capital e, portanto, acumular.

Se o capitalista pagasse pela força de trabalho o equivalente ao que é produzido pelo trabalhador, seu dinheiro não se transformaria em capital, tornando-se evidente que a contradição capital-trabalho é resultante de uma determinada relação social. Essa relação, historicamente, assume novas formas. Tendo em vista o seu fim e como o desenvolvimento tende a reduzir as taxas de lucro, as novas modalidades de trabalho aprofundam a exploração. Paradoxalmente, o avanço das forças produtivas não implica redução do tempo de trabalho. Ao contrário, malgrado o desenvolvimento tecnológico, o capital investe em modalidades de exploração que quer para si todo o tempo do trabalhador. Evocando a flexibilidade, o Estado se encarrega de dar legalidade às formas que rebaixam o custo do trabalho, ao tempo que elimina as conquistas garantidoras de proteção social.

Com base no exposto, se estivermos de acordo que capital e trabalho constituem uma relação social, haveremos de concluir que o capitalismo não é natural nem eterno: é o capital que precisa do 
trabalho e não o trabalho que precisa do capital. Embora os capitalistas comumente autodeclarem a sua importância social, por oferecerem postos de trabalho, na verdade, os trabalhadores é que são fundamentais, pois sem eles a riqueza do capitalista seria dizimada. Portanto, a perenidade ou o fim do capitalismo passa, obrigatoriamente, pela classe trabalhadora. Já o trabalho é eterna necessidade do homem. Daí a sua inquestionável centralidade.

Ante os argumentos expostos, eu me pergunto se estes seriam suficientes para convencer o trabalhador de que a riqueza existente é fruto do seu trabalho. Melhor, é fruto daquela parte do trabalho que o empregador não lhe paga. $\mathrm{O}$ trabalhador sentir-se-ia injustiçado e revoltado ao ponto de se propor a repensar os valores burgueses, ou tenderia a continuar pensando capitalisticamente? Afinal, via de regra, até o trabalhador defende que o capital empregado no empreendimento que lhe cria emprego deve ser remunerado. Isso conduz à triste constatação de que a tarefa de romper com os valores burgueses e, por conseguinte, contribuir com a formação do pensamento crítico não é só uma questão de vontade, nem está a depender de discursos. Pensar como socialista requer experiências revolucionárias, requer uma unidade que é cada vez mais difícil de ser alcançada, dadas as fragmentações operadas pela divisão do trabalho. Se n'O 18 de Brumário de Luís Bonaparte (2015), Marx caracterizou os camponeses como batatas juntas, mas separadas, incapazes de assumir um papel unificado na revolução, o que dizer dos trabalhadores neste século XXI? São tantas as formas de separação, que se tornou quase impossível falar de uma única classe trabalhadora. Aquela polêmica classe-que-vive-do-trabalho concebida, no final do século passado, por Ricardo Antunes (1999), é cada vez mais atual.

Exatamente por isso, neste século XXI, muito mais que antes, é imprescindível que os trabalhadores lutem pela unidade de classe, tendo claro, como já fora dito antes, que as respostas às questões do trabalho só podem ser encontradas no interior do desenvolvimento das relações de produção. Se estamos insatisfeitos, infelizes, indignados, estarrecidos com os caminhos escolhidos pelo capitalismo, se estamos a nos perguntar quanto mais suportamos de rebaixamento ao custo da força de trabalho, se rejeitamos a sociedade capitalista e todas as suas estratégias de acumulação, precisamos acompanhar de perto os movimentos do capital e assumir a nossa oposição à materialidade do neoliberalismo, expressa na funcionalidade do Estado ao capital.

O neoliberalismo me faz sentir saudades do liberalismo. Marx ironizou o reconhecimento que o liberalismo fez ao homem: "rebaixá-lo ao nível de uma força de trabalho destinada a criar riqueza" (2009, p. 88). Sem dúvida, a subjetividade humana não se restringe a tão pouco, contudo, objetivamente, no capitalismo, o homem foi reduzido à força de trabalho, à mercadoria. Se isso o diminui, se a sua dimensão humana é suprimida pelo liberalismo, o neoliberalismo o aniquila, pois uma das características que distingue esses dois momentos históricos é a atual negação do trabalho como fonte de riqueza. Subscrevo Dardot e Laval (2016), quando indicam que o neoliberalismo não é o herdeiro natural do primeiro liberalismo, mas também não é seu extravio nem sua traição.

O neoliberalismo não se pergunta mais sobre que tipo de limite dar ao governo político, ao mercado (Adam Smith), aos direitos (John Locke) ou ao cálculo da utilidade (Jeremy Bentham), mas, sim, sobre como fazer do mercado tanto o princípio do governo dos homens como o do governo de si [...]. Considerado uma racionalidade governamental, e não uma doutrina mais ou menos heteróclita, o neoliberalismo é precisamente o desenvolvimento da lógica do mercado como lógica normativa generalizada, desde o Estado até o mais íntimo da subjetividade. (DARDOT; LAVAL, 2016, p. 34).

Nesse contexto, parece procedente pensar o envelhecimento, ou a condição do trabalhador que está a envelhecer, sob as determinações de um padrão de desenvolvimento no qual as contradições internas põem em xeque o seu próprio modo de ser, nomeadamente o modo de produção capitalista, agravado pelo neoliberalismo. Note-se que, em tempo recorde, o que foi dado ao trabalhador com uma mão está a ser tirado com a outra. No caso brasileiro, em que a proteção social nem de longe se assemelha à do Estado de bem-estar social, muitos trabalhadores, provavelmente, nem chegarão a usufruir da aposentadoria, nos termos que lhes fora prometido. Paradoxalmente, o tempo de vida que lhes fora alargado pela qualidade de vida é, agora, justificativa para aumentar o seu tempo de trabalho, o que equivale à supressão da qualidade que parecem ter conquistado.

\section{Considerações Finais}

Para finalizar, quero apelar à coragem dos trabalhadores. Nesse sentido, penso que um bom exemplo prático de coragem é mais animador que todas as minhas elucubrações teóricas, embora não descarte a sua importância, no que tange ao conhecimento da realidade. Entre os homens (genericamente) que considero 
corajosos, destaco Pedro Casaldáliga ${ }^{2}$ (91 anos), “o bispo que não vai para o céu” (TAVARES, 2019). A mim não importa que ele não seja declaradamente um marxista, não importa que a sua luta esteja pautada pela religiosidade, desde que a sua prática exercite o caráter social e político da religião, que o coloca do mesmo lado em que estão os marxistas. A mim importa que sejam priorizadas as causas da vida e que essa motivação seja maior do que o medo. É dele esta afirmação: "O problema é ter medo do medo" (TAVARES, 2019).

Estamos todos amedrontados. Temos medo da violência urbana, temos medo dos efeitos da crise sobre os nossos empregos e, por conseguinte, sobre as nossas vidas; temos medo do Estado, uma vez que este, no seu propósito de defender a propriedade privada, está a "civilizar" as maneiras de matar e a "atribuir objetivos racionais ao próprio ato de matar" (MBEMBE, 2017, p. 126). Temos medo de envelhecer nesse mundo onde se cultivam a covardia, a delação e a resiliência.

Nosso medo não é irrazoável. Mas, como dizem Dardot e Laval (2016), "a nova razão do mundo não é um destino necessário que subjuga a humanidade" (Idem, p. 401). Não podemos sucumbir ao medo, tampouco ficar indefinidamente a ouvir o eco da nossa própria voz, uma vez que, em geral, estamos a falar para nós mesmos. A perspectiva teórico-metodológica que norteia as nossas análises também deve nortear nossas ações. Nesse sentido, parece que a saída é vencer o medo e seguir uma das lições de Casaldáliga: "A gente não joga rede em aquário, a rede a gente joga no mar" (TAVARES, 2019).

\section{Referências}

ANTUNES, R. Os sentidos do trabalho: ensaio sobre a afirmação e a negação do trabalho. São Paulo: Boitempo, 1999. BASSO, P. Tempos modernos, jornadas antigas: vidas de trabalho no início do século XXI. São Paulo, Campinas: Editora da UNICAMP, 2018.

BBC NEWS. Idosos na prisão: porque alguns aposentados estão se esforçando para ir para a cadeia no Japão. BBC News, Mundo, fev. 2019. Disponível em: https://g1.globo.com/mundo/noticia/2019/02/01/idosos-na-prisao-por-que-alguns-aposentados-estao-seesforcando-para-ir-para-a-cadeia-no-japao.ghtml. Acesso em: 5 maio 2019.

DARDOT, P., LAVAL, C. A nova razão do mundo: ensaio sobre a sociedade neoliberal. São Paulo, Boitempo, 2016.

GABRIEL, M. Amor e capital: a saga familiar de Karl Marx e a história de uma revolução. Rio de Janeiro: Zahar, 2013.

KUMAR, K. Da sociedade pós-industrial à sociedade pós-moderna: novas teorias sobre o mundo contemporâneo. Rio de Janeiro: Zahar, 1997.

MARX, K. Crítica do nacionalismo econômico. Lisboa: Antígona, 2009.

MARX, K. O capital: crítica da economia política. São Paulo: Abril Cultural, 1983. 140, L. 1, v. I.

MARX, K. Crítica da Filosofia do Direito de Hegel. São Paulo: Boitempo, 2010.

MARX, K. O 18 de Brumário de Luis Bonaparte. São Paulo: Boitempo, 2015.

MBEMBE, A. Políticas da inimizade. Lisboa: Antígona, 2017.

TAVARES, A. H. O bispo que não vai para o céu. Outras Palavras, abr. 2019. Disponível em: https://outraspalavras.net/outrobrasil/obispo-que-nao-vai-para-o-ceu/. Acesso em: 6 maio 2019.

\section{Notas}

1 Folguedo popular que encena o nascimento de Jesus.

2 Adepto da Teologia da Libertação, adotou como lema para sua atividade pastoral: nada possuir, nada carregar, nada pedir, nada calar e, sobretudo, nada matar. É poeta, autor de várias obras sobre antropologia, sociologia e ecologia.

\section{Maria Augusta Tavares}

entrementes73@gmail.com

Doutora em Serviço Social pela Universidade Federal do Rio de Janeiro (UFRJ)

Pesquisadora Integrada ao Instituto de História Contemporânea (IHC) da Universidade Nova de Lisboa (UNL)

\section{IHC/UNL}

Avenida de Berna, 26-C - Campus de Campolide

Lisboa - LX - Portugal

CEP: 1050-099 


\section{Agradecimentos}

A orientação, em regra, perspectiva o orientando. Às vezes, também o orientador. À Jô Carvalho, pela visibilidade ao tema.

Agência financiadora

Não se aplica.

Contribuições dos autores

Não se aplica.
Aprovação por Comitê de Ética e consentimento para participação

Não se aplica.

Consentimento para publicação

Não se aplica.

Conflito de interesses

Não há conflito de interesses. 